\title{
SPATIAL CHANGES AND POPULATION MOVEMENTS ON THE ALBANIAN COASTLINE
}

\author{
U. Kanjir ${ }^{\text {a, } * \text {, N. Gregorič Bon }}{ }^{\text {a }}$ \\ ${ }^{a}$ ZRC SAZU, Department of Remote Sensing, Novi trg 2, 1000 Ljubljana, Slovenia - \{ursa.kanjir, natasa.gregoric\}@zrc-sazu.si
}

Commission VIII, WG VIII/9

KEY WORDS: Change detection, urban growth, coastal erosion, migration, Albanian coastline, CVA, anthropology, multidisciplinary research

\begin{abstract}
:
The last decade has seen a large increase in construction along the southern Albanian coastline, mainly in the rise of large tourist complexes comprising hotels, apartment houses, touristic villages, and so on. These constructions rarely follow urban planning and not only change its landscape but also often threaten the ecological value of the coastal zone. The uncontrolled and devastating construction along the coast has been accompanied by coastal erosion caused by the sea with the intensity up to $50 \mathrm{~cm} / \mathrm{year}$. This paper investigates the environmental change monitoring on the Albanian Riviera by analysing optical remote sensing data (Landsat 5 and 8) in the period between 1984 and 2015. The image analysis results grounded on the change vector analysis indicate coastal morphology changes and land cover changes in the coastal environment, which appear mostly due to erosion in river delta and urban growth. Apart from identifying both phenomena through time, the objective of this study is to show that these landscape changes in fact correlate with the population migration as well as to explain why and the extent to which Albania is one of the most migratory countries in Europe. Based on the multidisciplinary research, which combines anthropological method with spatial analysis, this presentation anticipates future changes in this area. It argues that movements of both people and in landscape formations strongly influence each other, constituting a closely corresponding relationship.
\end{abstract}

\section{INTRODUCTION}

Nowadays there is large amount of environmental and social data available at relatively high spatiotemporal resolutions. Usually the data describes only some particulars of the complex socio-ecological systems, which influence the socioenvironmental changes. Deeper understanding of these complex systems requires several different approaches and a synthesis of various available data. Remote sensing technology for example can observe large areas of interest through different periods with relatively minimal if any costs at all and can offer profound insight into the dynamics of the observed area. This is especially important when dealing with areas that have had to face abrupt changes, as is the case with the Albanian coastline.

This paper explores the correlation between geomorphological (coastal erosion) and demographical changes along the southern Albanian coastline using remote sensing and socioeconomic data. We applied the change vector analysis (CVA) approach to the multi-temporal remote sensing (Landsat) data from four different pre-selected time slots on the Albanian coastline in order to detect two types of coastal changes: coastal erosion and coastal urbanisation. To describe population migration patterns for the particular time-periods we have used the INSTAT national statistical data.

Based on the analysis of the combination of above data, this paper proceeds to examine whether human and natural alterations of landscape could provide clues to the socioeconomic changes undergone by this area over the past decades. It argues that the correlation found between changes seen from optical satellite images and corresponding migration data of Albania from the last three decades could give us insight in to the complex environmental and social changes. This ongoing research involves using a multidisciplinary approach.

\subsection{Geomorphological and demographic changes}

Albania is a Mediterranean country with the coast stretching alongside the Adriatic Sea to the West and Ionian Sea to the Southwest. The country has over $400 \mathrm{~km}$ of coastline, of which approximately $150 \mathrm{~km}$ of its southern coastline is highly erosive (Gruda and Dollma, 2013) and of high ecological value. This entire stretch of southern coast, extending from Vlora to Ftelis Bay (Greece), is subject to intense erosion of about $20-50 \mathrm{~cm}$ per year (Qiriazi and Sala, 2000) and is characterized by rapid morphological changes resulting in an ongoing westward growth of the coastal lowland (Gruda and Dollma, 2013). The causes of coastal erosion are related to several general and local factors, both human (e.g. removal of inert materials from the riverbeds and coastline, unplanned constructions, hydrological construction on the shores) and naturally driven (e.g. coastal terrigenous material, steep slopes, river deposits, irregular precipitation). Some parts of coastal areas lack urban planning; furthermore, there is poor periodic control of erosion and hardly any legal regulation for coastal protection. In order to avoid further reducement of the ecological values on the coastal zone a precise land use planning should be performed in the area.

At the same time, the geomorphological movements that have been present in this area for centuries, the population movements, such as migrations, are not novel phenomena. Albania's population has been subject to migrations throughout the centuries. Vullnetari (2012) writes that according to social

\footnotetext{
* Corresponding author
} 
memory, the first mass resettlements took place already in the second half of the 15th century in the days of the Ottoman Empire. Vullnetari (2012) also estimated that around 200.000 people inhabiting the present-day territory of Albania moved to what are today Italy, the Dalmatian coast and southern Greece. Migrations still play a major role in the lives of many Albanians today, and the anthropological research has shown how migration is embodied in peoples' practices as well as reified in the Albanian architecture (Gregorič Bon, in press). In 1945 with the introduction of the communist regime, these movement practices were stopped for more than four decades as the Albanian communist regime forbade any state-border crossing. Most of the trading relations and travels outside Albania therefore became impossible. This has changed drastically after the fall of the communist regime in 1990, in the wake of which came mass movements of people, and material, financial and other resources. First mass migrations had epic proportions (King, 2005, Vullnetari, 2012). This has brought in various bureaucratic regimes, social stratifications and strategies over who can migrate and who cannot. These strategies had the contrary effect and brought about a rise in unauthorized migrations and enlarged the number of visa applications. Majority of migrations have postulated remittances to the migrants' country of origin. Remittances were often the main source of income for particular households and economies in Albania (Wong, 2006) and influenced the rapid urbanisation of the area.

\subsection{Population migrations through time}

For the purposes of detecting change, we have identified four important periods based on historical accounts, which have significantly influenced the population migration in this area:

- The first period extends from 1984 to 1990 and includes the period of the communist regime. When the totalitarian leader, Enver Hoxha, forbade private ownership of cars and limited the in-country movements, most of the mobility practices were stopped (Gregorič Bon, 2008, in press). In this period, due to the development of textile and food industry in Vlora, many people living in rural areas moved to this coastal city.

- The second period extending from 1991 to 2000 and marking the collapse of the communist regime saw major migration "exoduses" that have importantly influenced the Albanian politics, economy, society as well as the landscape. For example, on New Year's Eve in 1990, 800.000 citizens migrated to Greece and Italy (de Zwager et al., 2005). Another mass "migration episode" took place in 1997 with the collapse of the pyramid investment schemes, which led the country into anarchy and social unrest, while another one corresponds with the Kosovo political and economic crisis of 1999 and 2000 (Vullnetari, 2012).

- The third period extends from 2001 to 2010, when the number of migrants stabilised whereas the number of remittances and other material goods sent sporadically to home location increased.

- The fourth period extends between 2011 and 2015. In December 2010, Albania became part of the Schengen Zone area, which had a stabilizing effect on migration. Due to fiscal and economic crisis in Greece and Italy, many migrants began to return. Between 2010 and 2011, the INSTAT national statistical database reports the largest number of return migration in relation to the total population living in Vlora (INSTAT, 2016). The remittances and real-estate investments increased. Since 2010, Vlora coastal district has seen rapid urbanization, which in turn has increased the erosion process in this area.

\subsection{Past studies of spatial movements and migration}

According to the scholarly literature Albania is one of the countries with highest erosion and migration in Europe (Grazhdani and Shumka, 2007, Buchroitner, 2000, King, 2005, Vullnetari, 2012). Change detection using remote sensing data relates to the process of identifying and examining temporal, spatial and spectral changes of the pixel signal. Studies of change detection using change vector analysis from Landsat data have been done by several scholars (e.g. Xiaolu and Bo, 2011, Baker et al., 2007, Lorena et al., 2002, Allen and Kupfer, 2000), but most of them focus on forest detection or general land use/land cover detection. To our knowledge no literature exists, that would combine remote sensing with an anthropological approach and explore the correlation between coastal erosion and population migration in the coastal areas. A few studies have dealt, for example, with the effects of population density on soil erosion (Bilsborrow, 1992) or spatiotemporal differences of urban land expansion and arable land loss among different areas and the cities (Minghong et al., 2005). Several other studies have dealt with migration population, but none of them has tried to correlate this phenomenon to soil or coastal erosion.

Based on the multidisciplinary approach this papers seeks to analyze two major issues: is there a correlation between landscape changes along the Albanian coastline and population migrations through time?

\section{STUDY AREA AND DATA USED}

\subsection{Study area}

Our study area focuses on the coastal part of southern Albania. We undertook the analysis from the city of Vlora in the north and the city of Saranda in the south, with a particular focus on the city of Vlora, which has been subject to population movements since the 6th century BC. Historically it is an important city, as it was from this city that the Albanian Declaration of Independence was proclaimed in 1912. Today Vlora is the second largest port in Albania (after Durres in the north) with a significant fishing and industrial base. After the fall of the regime, this municipal seat of the County has also become a significant tourist destination.
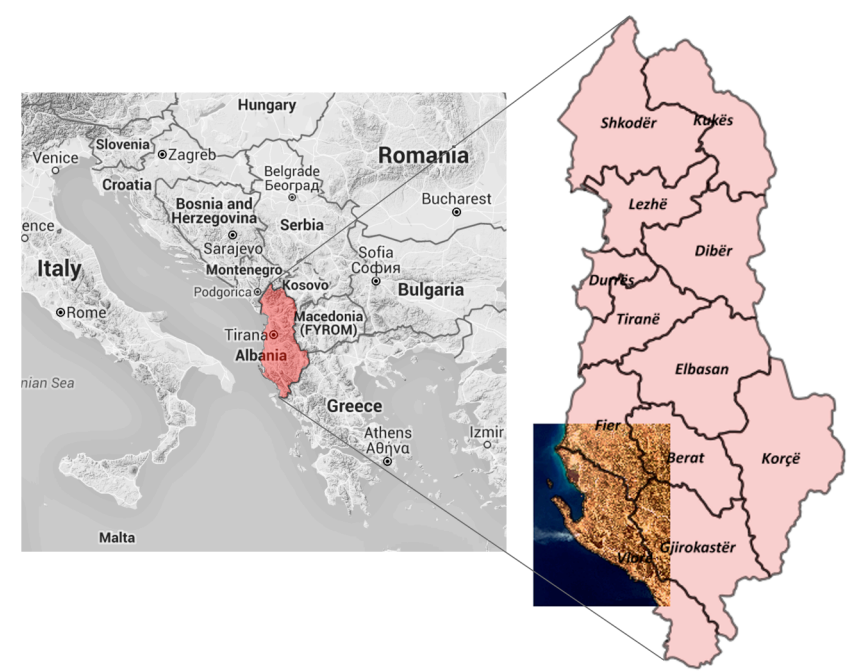

Figure 1. Location map of the study area. 
Figure 1 shows the position of Albania on the map of Southeastern Europe (Figure 1, left). On the right part of the Figure 1, an enlarged scale of the country and extent of satellite image over twelve major counties is shown.

\subsection{Data used}

In this study, we have used the combination of Landsat 5 and 8 satellite images for the selected years, taken during the same season (all images were acquired in late August or early September). Multispectral images have $30 \mathrm{~m}$ of spatial resolution.

The combinations of images compared between designated periods are listed in the Table 1 below.

\begin{tabular}{|c|c|c|}
\hline Period & $\begin{array}{c}\text { Image } \\
\text { combinations }\end{array}$ & $\begin{array}{c}\text { Used Landsat } \\
\text { sensor }\end{array}$ \\
\hline Period 1 & $1984-1990$ & Landsat 5 \\
\hline Period 2 & $1991-2000$ & Landsat 5 \\
\hline Period 3 & $2001-2010$ & Landsat 5 \\
\hline Period 4 & $2011-2015$ & $\begin{array}{c}\text { Landsat 5 - } \\
\text { Landsat 8 }\end{array}$ \\
\hline
\end{tabular}

Table 1. The satellite sensor images used for change detection analysis and time periods compared.

Before doing the multi-temporal analysis of multispectral images, the images were atmospherically corrected using ATCOR software. The objective of applying an atmospheric correction is to determine true surface reflectance values by removing atmospheric effects from satellite images (Hadjimitsis et al., 2010). These corrections are important especially when comparing multi-temporal images (Jianya et al., 2008), and therefore when using change vector analysis, as this technique is based on pixel-wise radiometric comparison.

Images were also geometrically aligned between each other before the analysis. The importance of accurate spatial registration of multi-temporal imagery cannot be overstated, since misregistration will give rise to false results. If high registration accuracy is not available (sub-pixel), image displacement will lead to inaccuracies in change detection scene.

Images were finally cropped to the desired geospatial extent corresponding to our study interest.

We gathered the data concerning migration flows in Albania from the INSTAT national statistical database.

\section{METHODOLOGY}

The remote sensing analysis for change detection was implemented entirely with the use of open source software R. To obtain change detection between selected periods we have used change vector analysis (CVA) methodology, which is a simple and effective method for change detection.

\subsection{Change vector analysis}

Change vector analysis (CVA) is a valuable technique for landuse/land-cover change detection. CVA uses two spectral channels and calculates the magnitude of change and the direction of change between these two images (Malila, 1980). The greater is the magnitude, the higher is the possibility of change. The direction of magnitude can be examined further and with the use of a vector angle, the analyst can get the information on the type of change in two spectral dimensions (Chen et al., 2003). Changes are therefore shown as multidimensional spectral vectors. Based on whether the change magnitude exceeds a specific threshold, the analyst comes to a conclusion on the change. Spectral change vector analysis can avoid not only the classification and time-consuming effort and the accumulated error in the type of unreasonable defect in postclassification comparison method, but can also use more or even all of the bands to detect changes in pixels, and the changes in pixel type information (Lorena et al., 2002).

In order to reduce the amount of redundant information for the detection of coastal erosion and urbanisation in our study area, we have not used the combination of satellite spectral bands directly, but rather the combination of different indexes. For the coastal erosion detection, we have used the combination of Normalized Difference Water Index (NDWI) and Normalized Difference Urban Index (UI) - or also called the build-up index (Zha et al., 2003). Further, for the needs of urbanisation growth detection through time CVA we applied Normalized Difference Vegetation Index (NDVI) in combination with UI indexes.

NDWI is used to monitor changes related to water content in water bodies and it uses the information extracted from green and near infrared (NIR) bands. As a result, water features are enhanced owing to having positive values and vegetation and soil are suppressed due to having zero or negative values (McFeeters, 1996).

$$
N D W I=\frac{\text { Green }-N I R}{\text { Green }+N I R}
$$

UI gives the presentation of urban areas with the use of higher SWIR (short wave IR) and NIR bands of optical images, since built-up lands and bear soil (e.g. beach) have higher reflectance in SWIR wavelength range than in NIR wavelength range.

$$
U I=\frac{S W I R-N I R}{S W I R+N I R}
$$

NDVI also takes advantage of NIR and red bands and is sensitive to detecting vegetation.

$$
N D V I=\frac{N I R-N I R}{N I R+\mathrm{R}}
$$

These combinations of indexes in the coastal area of Albania proved to be the best option for detecting changes, which are the objective of our study.

Subsequently, the analyst comes to a decision about change based on whether the change magnitude exceeds a specific threshold. A threshold determination for change and non-change pixels while using the combination of indexes for the CVA in change detection variations was empirically selected to the value 0,2 for the coastal erosion and 0,4 for the urbanisation growth detection. The determination of the optimal threshold is considered as the most important task as well as the greatest challenge of CVA (Smits and Annoni, 2000), and usually requires a more experienced image analyst (Bruzzone and Prieto, 2000).

Results for both types of change in the coastal area of southern Albania from remote sensing data were later compared with the statistical data of migrations that happened since the date of the 
first available satellite image from 1984 up until 2015. The next chapter presents the results.

\section{RESULTS}

\subsection{Coastal erosion}

Strong erosion has affected Albanian coastline in many areas. Our study has detected these changes and shown where in the Southern Albanian region they were most prominent. The darker areas on the coast show higher magnitude (or higher chance) of coastal changes between the selected dates.
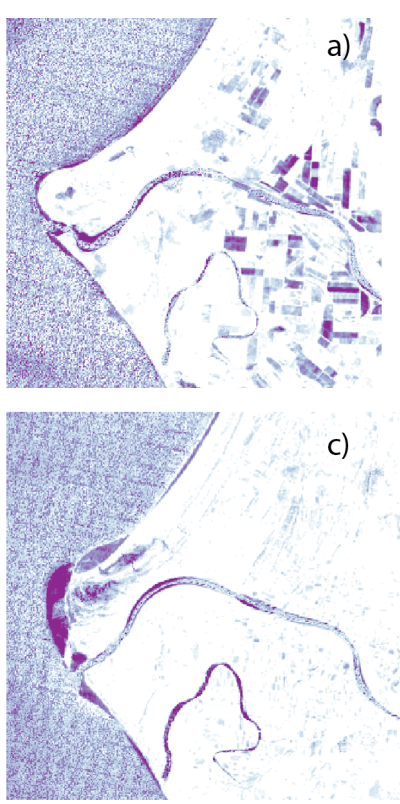
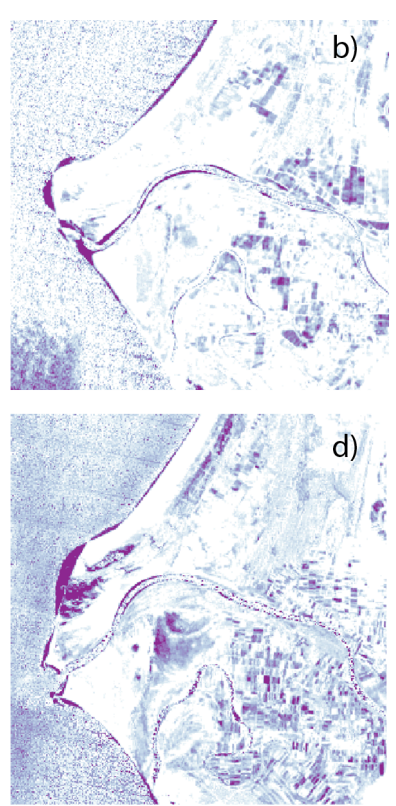

Figure 2. Changes of the coastal erosion through time in delta of Vjosa River. The greater the change, the darker the representation on the image. The Figure presents changes between years a) 1984-1990, b) 1991-2000, c) 2001-2010 and d) 2011-2015.

Satellite images analysis results indicate that erosion areas have increased substantially. Obvious delta shape changes of Vjosa River have resulted from the interaction between sediment discharge by the river, anthropogenic removal of coastal sediment, wave energy and tidal effects.

\subsection{Urban change}

The extent of changes to the town of Vlora was shown to be smaller than that brought about by coastal erosion in the delta of Vjosa River, which was to be expected, due to lower spatial extend of constructions in the city comparing to the historical natural river delta land movements. Nevertheless, urbanisation along the Albanian coast has been on a rapid increase since the late $1990 \mathrm{~s}$, which is when emigrants' revenue started to grow. Figure 2 shows the changes taking place in our periods. Because of the increase in urban migrations, there has been an increase in urban residues, with the biggest change taking place between 1990 and 2000 (Figure 2b).
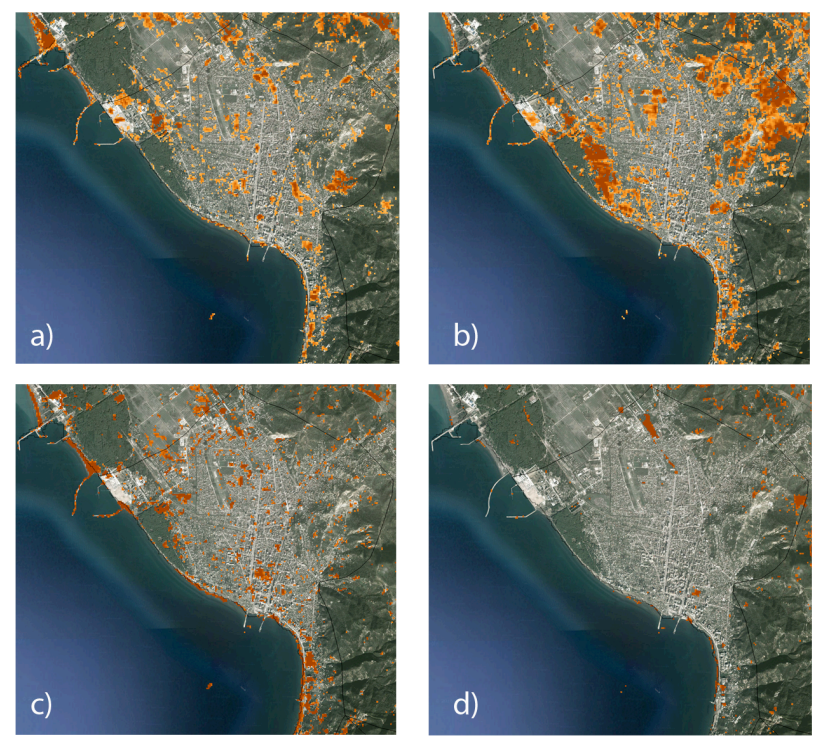

Figure 3. Changes of the urban areas through time in the city of Vlora. The Figure presents changes in the periods of 1984-1990 (a), 1991-2000 (b), 2001-2010 (c) and 2011-2015 (d). Background layer on all sub-images is Google Earth image from 2015.

\subsection{Correlation of the spatial and socioeconomic results}

When comparing the socio-economic data with the results from the remote sensing change detection analysis, we can see that the changes of both land changes and migration flows correspond with each other. Through all four-time periods all the change extensions confirm the situation in the country (see Table 2).

\begin{tabular}{|c|c|c|}
\hline Date & Socioeconomic statistics & $\begin{array}{l}\text { Remote sensing } \\
\text { analysis change } \\
\text { detection results } \\
\text { (max width of } \\
\text { coastal change) }\end{array}$ \\
\hline Period 1 & $\begin{array}{lr}\text { Forbidden } & \text { out country } \\
\text { migrations, } & \text { limited and } \\
\text { controlled } & \text { in-country } \\
\text { migrations } & \end{array}$ & $<100 \mathrm{~m}$ \\
\hline Period 2 & massive migrations & $<180 \mathrm{~m}$ \\
\hline Period 3 & $\begin{array}{lr}\text { stabilized } & \text { migration, } \\
\text { remittances, growing no. of } \\
\text { returnees, } \\
\text { migration }\end{array}$ & $<400 \mathrm{~m}$ \\
\hline Period 4 & $\begin{array}{l}\text { Stable, the no. of } \\
\text { migrations rises again in } \\
2014\end{array}$ & $<150 \mathrm{~m}$ \\
\hline
\end{tabular}

Table 2. Comparison of the data on migration and remote sensing change detection results.

First period is marked with almost no migrations and only slight environmental changes. The most extensive migrations took place in the period 2, where at the same time river mouth mass changes of Vjosa substantially increased in comparison to the first period (up to 180 meters), and the urbanisation growth is the most extensive in this era. The biggest environmental changes in Vjosa river are detected in the period 3 (up to 400 meters in width) when the migrations are stabilizing but remittances are at their highest, resulting in the most intense urbanisation growth in the Vlora area so far. In period 4, when only five years and not the whole decade has been taken for 
consideration, both migration and environmental changes are still under progress, but up to a much smaller extent than in the previous periods.

\section{CONCLUSION}

The analysis of satellite data and the research of the population migration along the Albanian southern coastline is characterized by complex landscape changes that were caused by different factors, both natural and anthropogenic, interacting with each other, and resulting in multiple consequences. Our results of coastal changes driven by coastal erosion in the studied area confirm the findings of authors Qirazi et al. (2000). They mention strong coastal erosion $(20-50 \mathrm{~cm} /$ year $)$ along the entire southern Albanian coastline (from Vlora region to Greece).

In this study we have shown that the environmental changes (coastal erosion and urbanization growth) correspond to the social, political, economic and demographic changes of Albania during the period under study (1984 - 2015). Therefore, the changes seen in the environment strongly indicate larger socioeconomic, political and demographic changes taking place within the state.

This research has shown that for the purpose of further research of (co)relation between spatial and anthropogenic factors in the area we need to integrate more historical data into our research so as to define the problem in a more long-term perspective. We plan to conduct a fieldwork investigation with which we aim to obtain reference data for the degree of change taking place in the area, not only from the perspective of migrations but also from the perspective of spatial changes and transformations. The goal is to quantify the extent of changes and their directions as detected from remote sensing data, and subject them to a statistical analysis. Moreover, we will try to see how these changes might influence future changes. We also plan to work in the direction of obtaining other types of data integration that will help us understand more holistically the movements in and changes to both the area and its people in the southern Albania.

\section{ACKNOWLEDGEMENTS}

This research has been funded by the Slovenian Research Agency (2014-2017).

\section{REFERENCES}

Allen, T.R., Kupfer, J.A., 2000. Application of Spherical Statistics to Change Vector Analysis of Landsat Data: Southern Appalachian Spruce-Fir Forests. Remote Sensing of Environment, 74(3), pp. 482-493.

Baker, C., Lawrence, R. L., Montagne, C., Patten, D., 2007. Change detection of wetland ecosystems using Landsat imagery and change vector analysis. Wetlands, 27(3), pp. 610-619.

Bilsborrow, Richard E., 1992. Population growth, internal migration, and environmental degradation in rural areas of developing countries. European Journal of Population / Revue européenne de Démographie, 8(2), pp. 125-148.

Bruzzone, L., Prieto, D.F., 2000. Automatic analysis of the difference image for unsupervised change detection. IEEE Transactions on Geoscience and Remote Sensing, 38(3), pp. 1171-1182.

Buchroitner, M. F., 2000. Remote Sensing for Environmental Data in Albania: A Strategy for Integrated Management.
Springer Science and Business Media Dordrecht, originally published by Kluwer Academic Publishers.

Chen, J., Gong, P., He, C., Pu, R., Shi, P., 2003. LandUse/Land-Cover Change Detection Using Improved ChangeVector Analysis. Photogrammetric Engineering \& Remote Sensing, 69(4), pp. 369-379.

Grazhdani, S., Shumka, S., 2007. An approach to mapping soil erosion by water with application to Albania. Desalination 213, pp. 263-272.

Gregorič Bon, N., 2008. Prostori neskladij: Etnografija prostora in kraja v vasi Dhërmi/Drimades, južna Albanija. Ljubljana, Založba ZRC.

Gregorič Bon, N., in press. Rooting Routes. (Non-)Movements in Southern Albania. In: Moving Places. Relations, Return and Belonging, Gregorič Bon, N. and Repič, J. (Eds.). Oxford, New York: Berghahn Books.

Gruda, G., Dollma, M., 2013. Albania. In: Coastal Erosion and Protection in Europe, Pranzini, E., Williams, A.T. (Eds). Routhledge, USA, Canada, pp. 345-354.

Hadjimitsis, D. G., Papadavid, G., Agapiou, A., Themistocleous, K., Hadjimitsis, M. G., Retalis, A., Michaelides, S., Chrysoulakis, N., Toulios, L., Clayton, C. R. I., 2010. Atmospheric correction for satellite remotely sensed data intended for agricultural applications: impact on vegetation indices. Nat. Hazards Earth Syst. Sci. 10, pp. 89-95.

INSTAT, 2016. Instituti i Statistikave Tiranë, http://www.instat.gov.al/al/figures/statistical-databases.

Jianya, G., Haigang, S., Guorui, M., Qiming, Z., 2008. A review of multi-temporal remote sensing data change detection algorithms. Int. Arch. Photogramm. Remote Sens. Spat. Inf. Sci 37, pp. 757-762.

King, R., 2005. Albania as a laboratory for the study of migration and development. Journal of Southern Europe and the Balkans, Special Issue: New Perspectives on Albanian Migration and Development, VII 2, pp. 133-155.

Lorena, R. B., Santos, J.R., Shimabukuro Y.E., Brown, I.F., Kux, H. J. H., 2002. A change vector analysis technique to monitor land use/land cover in SW Brazilian amazon: Acre state. In: PECORA 15-Integrating Remote Sensing at the Global, Regional and Local Scale, Denver, CO, USA, pp. 8-15.

Malila, W.A., 1980. Change vector analysis: an approach for detecting forest changes with Landsat. In: Proceedings of the 6th Annual Symposium on Machine Processing of Remotely Sensed Data, $3^{\text {rd }}-6^{\text {th }}$ June, Purdue University, West Lafayette, Indiana, pp. 326-335.

McFeeters, S.K., 1996. The use of normalized difference water index (NDWI) in the delineation of open water features. International Journal of Remote Sensing, 17(7), pp. 1425-1432.

Minghong, T., Xiubin, L., Hui, X., Changhe, L., 2005. Urban land expansion and arable land loss in China-a case study of Beijing-Tianjin-Hebei region. Land Use Policy, 22(3), pp. 187-196.

Qiriazi, P., Sala, S., 2000. Environmental problems of Albania. In: Buchroithner, M.F. (Ed.), Remote sensing for environmental 
data in Albania: a strategy for integrated management, Kluwer, Dordrecht, pp. 13-30.

Smits, P.C., Annoni, A., 2000. Toward specification-driven change detection. IEEE Transactions on Geoscience and Remote Sensing, 38(3), pp.1484-1488.

Vullnetari, J., 2012. Albania on the Move. Links Between Internal and International Migration. IMISCOE Research, Amsterdam, Amsterdam University Press.

Zha, Y., Gao, J., Ni, S., 2003. Use of normalized difference built-up index in automatically mapping urban areas from TM imagery. International Journal of Remote Sensing, 24(3), pp. 583-594.

de Zwager, N., I. Gedeshi, E. Germenji, C. Nikas, 2005. A Study on Competing for Remittances. IOM, Tirana, Albania.

Wong, M., 2006. The gendered politics of remittances in Ghanaian transnational families. Economic Geography, 82(4), pp. $355-381$.

Xiaolu, S., Bo, C., 2011. Change detection using Change Vector Analysis from Landsat TM images in Wuhan. Procedia Environmental Sciences, 11(A), pp. 238-244. 